\title{
Comparative Social Capital: Networks of Entrepreneurs and Venture Capitalists in China and Russia
}

\section{Bat Batjargal}

Harvard University, USA, and Peking University, China

\begin{abstract}
I compare networks of entrepreneurs and venture capitalists in China and Russia by examining professional social networks of software entrepreneurs and private equity investors from the perspectives of institutional theory and culture paradigm. In the empirical study, I draw on survey data from Beijing and Moscow based on interviews of 159 software entrepreneurs and 124 venture capital decisions. I found that professional networks of the Chinese software entrepreneurs are smaller, denser and more homogeneous in educational specializations, compared with the networks of Russian entrepreneurs. Furthermore, I found that both ties and interpersonal trust in the referral tie are stronger in China than in Russia.
\end{abstract}

KEYwords China and Russia, culture, entrepreneur, institution, social capital

\section{INTRODUCTION}

How do institutions and national cultures relate to the social capital of entrepreneurs and venture capitalists in the comparative contexts of China and Russia? Social capital refers to the relationships, resources and assets embedded in social networks (Bourdieu, 1986). In this study, I contrast social network structure and relations of Chinese and Russian entrepreneurs and venture capitalists from the perspectives of institutional theory and culture paradigm. I argue that comparative social capital defined as the real and perceived differences and similarities in social network structures, relations and resources between nations, regions, localities, organizations, groups and individuals is a reflection of different institutional frameworks and national cultures.

The previous research on social networks had focused on the antecedents as well as the consequences of personal networks (Brass et al., 2004). Scholars identified that actor similarity in demographic characteristics, e.g., gender, (Brass, 1985) and proximity and organizational structure (Borgatti and Cross, 2003) predict network 
patterns and relations. Thus, researchers established that personal characteristics and micro-social environment, i.e., groups and organizations, influence networks of individuals. However, social networks are deeply embedded in local histories, institutions and cultures because actors build and mobilize networks at concrete geographical locations and times.

There are few studies that examined effects of national cultures and institutions on personal network formation (Brass et al., 2004). Burt et al. (2000) found that French managers were less comfortable with bridge relationships, i.e., a manager has relationships with two people who are not connected between themselves, than were US managers. To contribute to the comparative analysis of social networks, I compare network structure and relations of Chinese and Russian entrepreneurs and investors by using institutional theory and culture paradigm, because institutions and national cultures may influence network patterns, which in turn may affect important outcome variables such as firm performance, job attainment and career advancement.

A systematic review of the literature on entrepreneurs' networks shows that most studies on this theme incorporate social networks as independent variables that affect entrepreneurial outcomes (Batjargal, 2006). However, structural and relational patterns of entrepreneurial networks as dependent variables are important phenomena that should be explained. This study examined networks of entrepreneurs and investors as outcomes.

The social phenomenon called guanxi (connections) is the Chinese version of social networks (King, 1991). Although there is some debate about many nuances of guanxi, there is an agreement among scholars on its main meaning: guanxi is interpersonal relationships that facilitate or constrain social exchanges (Tsui et al., 2000; Yang, 1994). Researchers found that guanxi relationships to promote interpersonal trust (Farh et al., 1998) facilitate job mobility (Bian, 1997), affect investment decisions (Batjargal, 2007a; Batjargal and Liu, 2004) and enhance firm performance (Batjargal, 2003a,b, 2007b; Park and Luo, 2001).

The Russian version of social capital is svyazi, which literally means connections (Efremova, 2000; Yakubovich, 2005). The empirical research on Russian networks revealed that soyazi networks reduce uncertainties in financial transactions (Guseva and Rona-Tas, 2001), facilitate revenue growth (Batjargal, 2001, 2003b, 2005) and enable entrepreneurs to access resources (Sedaitis et al., 1998).

The literature on Chinese and Russian networks, however, has overlooked correlates of guanxi and svyazi networks in general, and antecedents of Chinese and Russian professional networks in particular. The revolutionary institutional changes in Russia, i.e., the replacement of the communist regime by a multiparty democracy, and the evolutionary institutional transformation in China, i.e., the incremental changes in the existing communist institutions, may have contrasting effects on the social networks of Chinese and Russian entrepreneurs and inves- 
tors. The largely Orthodox Christian culture of Russia and the predominantly Confucian culture of China may affect some elements of entrepreneurs' social networks. These contextual factors such as institutions and cultures are likely to produce differences in the guanxi and syyazi networks of entrepreneurs in China and Russia. This study attempts to answer the simple question of whether and how do the networks of entrepreneurs and venture capitalists differ in China and Russia. The principal argument is that different institutional frameworks and national cultures are related to contrasting network structures and relations because social actors build and mobilize networks in concrete historical, institutional and cultural environments.

\section{CONCEPTUAL FRAMEWORK AND HYPOTHESES}

\section{Institutional Transformation in Ghina and Russia}

Institutions are defined as multifaceted, durable social structures composed of regulative, normative and cultural-cognitive elements (Scott, 2001), and institutional transformation is regarded as changes in the formal regulations and norms that influence actors' behaviours. China and Russia as transition economies are experiencing unprecedented institutional changes. This institutional transformation is characterized as a dual process: On the one hand, it is a deinstitutionalization process that is reflected in the erosion and discontinuity of institutionalized organizational activities and practices (Oliver, 1992). However, this is also an institutionalization process that is reflected in the growth of novel regulative rules and norms that constrain actors' behaviours (Scott, 2001).

Deinstitutionalization refers to the delegitimation of established rules, structures and organizations. Specifically, deinstitutionalization is the process by which the existing procedures, structures and organizations are rejected, discredited and dismantled, due to political, economic and social pressures (Droege and Johnson, 2007; Oliver, 1992). On the contrary, institutionalization is the creation and legitimization of new and emerging regulations, structures and organizations. Institutionalization is the process by which growing regulative, normative and organizational elements gain appropriateness, acceptance and creditability. Therefore, institutionalization is driven by the rule-setting, the self-reinforcing feedback dynamics of legitimacy and the taken-for-grantedness of novel systems and organizations (Colyvas and Powell, 2006). The legitimization process is reflected in the standards of desirability, norms of appropriateness and clearly defined boundaries of growing regulations, frameworks and organizations. The emerging institutional structures become taken-for-granted when the new procedures and practices are consolidated; the novel roles are habitualized with expectations and the flourishing categories and classifications are settled. 
Although the dual processes of institutionalization and deinstitutionalization are occurring in China and Russia simultaneously, the Chinese transformation may be described as a gradual institutionalization process, whereas the Russian transition may be regarded as a rapid deinstitutionalization process.

In contrast to Russia, China has adopted the reform path of gradualism that resulted in the limited political reforms, staged economic liberalization and sequenced privatization. The Chinese leadership carried out simultaneous political centralization and fiscal decentralization (Shleifer, 2005). The Chinese communist institutions were not discredited. On the contrary, they were reformed and revitalized and, arguably, gained some legitimacy among the population. The Communist Party abandoned the ideology of class struggle and admitted private entrepreneurs to broaden its social base. While the party has consolidated its absolute dominance of the legislature, ministries, local governments, judiciary, media, security forces and military, it effectively transferred power in areas of economy, education and culture to non-party bureaucracies. The newly emerging organizations such as regulatory agencies, financial institutions and private firms are respected in China. In this way, the dual processes of the emergence of new rules and the survival of the old institutions provided China with institutional stability. Thus, China blends a communist political system with a capitalist market economy. The rising institutional framework in China is of a hybrid type of communist-capitalist regulations, norms and organizations (Nee, 1992; Scott, 2000).

In contrast to China, Russia has chosen the path of rapid political and economic liberalization and massive privatization of state-owned enterprises. Russia quickly replaced the communist political system with a multi-party system and carried out political decentralization that shifted much of the political power from the centre to local governments, creating a power vacuum (Shleifer, 2005). Furthermore, the Russian federal government introduced a series of rules and mechanisms that were designed to control Russia's regions fiscally through new systems of budget and taxation. While the Russian political reforms and fiscal federalism policies dismantled the Soviet-type rules and organizations, they did not create effective democratic and market oriented norms, structures and organizations. For example, the Russian financial institutions and oligarchic firms that grabbed assets through the dubious privatization schemes are widely distrusted and despised because of the persistent economic crises, inflation and corruption (Spicer and Pyle, 2002). Thus, Russia's institutional framework can be characterized as a condition where the old norms and organizations were deinstitutionalized and the new rules and structures are ineffective and illegitimate.

The institutional void prevailing in Russia is a reflection of deinstitutionalization, and the institutional continuity prevalent in China is an indication of institutionalization. They are likely to affect network patterns and relations because social interactions emerge and sustain in the context of existing institutional structures (Hitt et al., 2004). 


\section{National Cultures in China and Russia}

National cultures when defined as the collective programming of the mind and similar thinking, distinguish the members of one category of people from those of another (Hofstede, 1984); they also affect managerial values and ethics (Ralston et al., 1997). Embedded in Confucianism, the Chinese national psyche differs sharply from the Russian mindset. Postulates such as the reality of the universe and man's life in it; all forms of change are expressions of two forces, the yin and the yang; change takes place in the form of cycles or spirals rather than extremes, are fundamental metaphysics of the Chinese thinking. Most Chinese people are inclined to think concretely rather than abstractly, emphasize the particular rather than the universal, focus on practicality, and are concerned with reconciliation, harmony and balance (Redding, 1990). Understanding is based on appreciation and liking rather than analysis and calculations.

In contrast, the Russians are Orthodox Christians and keen abstract thinkers. Transcendental considerations and mysticism have an important place in their psyche (Graham and Kantor, 2006). They are more likely to emphasize the universal, focus on the general and prefer rational and quantitative analysis rather than intuition and contemplation in comparison with the Chinese. Russians are more tolerant of uncertainties and comfortable absorbing mutually exclusive and contradictory thoughts and mental positions. These differences in national cultures and psyche may be reflected in contrasting network patterns and relations, including network size, density, tie strength and trust in network members.

\section{Hypotheses}

The gradual institutionalization that sustained the old structures and organizations, and nurtured the rise of the new rules and structures, enabled social actors, including private entrepreneurs, to preserve their job related networks over time (Dai, 2002). The institutional and organizational continuity reduced perceived uncertainties and membership turnover in Chinese networks. For example, 80 percent of Chinese entrepreneurs regarded local, regional and central governments as favourable toward entrepreneurs whereas roughly 50 percent of Russian entrepreneurs regarded governments as favourable towards them (Djankov et al., 2006). Therefore, institutions and organizations in China did not lose their legitimacy.

Furthermore, in China the rigid household registration system, hukou, and the state employment system, danwei, constrain free flows and migrations of people between different localities. This restricts professional networking opportunities. In a survey study, Djankov et al. (2006) found that Chinese entrepreneurs had lived in fewer localities and held fewer distinct professional activities than did their Russian counterparts.

The Chinese have inherent cultural inclinations to prefer fewer yet trusted particularistic ties (Farh et al., 1998). Chinese networks are composed of more 
family members, colleagues, schoolmates and close friends due to the prevalent role of guanxi - the propensity to form relationships based on a common background, i.e., ancestral origin and classmateship (Redding, 1990). The guanxi base imposes clear boundaries on network membership and limits the pool of potential members to those who meet the criteria for being a member of a particular guanxi cluster (Tsui et al., 2000). Previous research has showed that most high-tech entrepreneurs in Beijing have resided in the Zhongguancun industrial district for many years, are graduates of prestigious universities and former researchers of the Chinese Academy of Sciences (Segal, 2003). They are likely to keep in touch with those guanxi ties who are considered in-group members (Tsui and Farh, 1997).

In contrast, Russian reforms resulted in the violent destruction of existing organizations, regional and industry-wide networks, and professional associations (Blanchard and Kremer, 1997). This forced Russian entrepreneurs to create new networks and clusters that serve as substitutes for nonexistent or weak institutions (Sedaitis et al., 1998). This may have increased the size of personal networks over time. Arguably, Russian society is more mobile both horizontally and vertically because of the more liberalized labour market and the elimination of the residential permission system. Previous research has found that Russian entrepreneurs were more mobile than their Chinese counterparts (Djankov et al., 2006). This mobility has created greater opportunities for professional networking. Russians are less particularistic and more individualistic than are the Chinese (Ralston et al., 1997). Social distances between members of in- and out-groups are not clear-cut in Russian networks and, therefore, Russian entrepreneurs are likely to have greater numbers of ties in their social networks than Chinese entrepreneurs.

For the above reasons, I expect that professional networks of Chinese entrepreneurs would be smaller than those of Russian entrepreneurs.

\section{Hypothesis 1: Network size of Chinese entrepreneurs is smaller than that of Russian entrepreneurs.}

The professional networks of Chinese entrepreneurs are also likely to be denser than those of their Russian counterparts. Network density is the mean strength of connections among the ties in a network (Marsden, 1990). The continuing takenfor-grantedness of the old organizations and the gradual legitimization of new rules enabled the Chinese to keep close and frequent contacts with their friends and acquaintances. The guanxi networks are more transitive - a tendency that one's friends' friends are likely to become one's own friends over time (Batjargal, 2004). In China, members of a particular guanxi cluster are expected to fulfil their role obligations and demonstrate group solidarity (Farh et al., 1998; Lin, 2001). For example, sixty percent of Chinese entrepreneurs agreed with the statement 'friends are very important', whereas forty percent of Russian entrepreneurs agreed with the same statement (Djankov et al., 2006). 
In contrast, the dismantling of the massive Soviet bureaucracies, privatization of state-owned enterprises, layoffs and downsizing lead to unemployment and displacement (Blanchard and Kremer, 1997). This is reflected in loose-knit networks. Relational base as a networking norm is not as prevalent as it is in China and, therefore, networking activities are less structured and planned. Russian networks are more hierarchical in terms of members' power and status. This generates greater relational distance among network members. Social sanctions used to punish deviant behaviour are less effective and, therefore, the Russians have greater autonomy in their networking efforts (Ledeneva, 1998).

Network density and structural hole, defined as the absence of a link between two contacts who are both linked to an actor (Brass et al., 2004; Burt, 1992), are two sides of one continuum. Hence, the dense Chinese networks should have fewer structural holes than the dispersed Russian networks rich in structural holes.

Social stability in China is conducive to sustainable socializations of actors and, in this way, it made the guanxi networks redundant and overlapping. For example, many former bureaucrats and scientists who become entrepreneurs in Beijing's Zhongguancun high-tech district stayed in touch with their old colleagues (Segal, 2003). The Chinese make greater efforts to reduce uncertainties and inconsistencies in their immediate social worlds and, therefore, networks of Chinese entrepreneurs are likely to have fewer structural holes. Brokerage between two contacts and playing off one contact against another is perceived as manipulative in China (Xiao and Tsui, 2007) and, therefore, the Chinese entrepreneur will not take deliberate actions to keep contacts apart, resulting in fewer structural holes in guanxi networks. Russian syyazi networks are less transitive because there is less trust embedded in the relationships (Petrovskii, 1991). Brokerage is more accepted and, hence, the Russians are likely to keep contacts disconnected to maximize gains from their intermediate positions.

Hypothesis 2: Network density of Chinese entrepreneurs is greater than that of Russian entrepreneurs.

The socialist mental models and schemes have not lost their legitimacy and influence in China (Scott, 2000), and the symbiotic integration of the socialist and capitalist ways of thinking may lead to similar mindsets among network members. Knowledge homogeneity in the guanxi networks is greater because many network members are classmates who studied the same subjects (Farh et al., 1998). In addition, homophily as a social selection mechanism favours those who are similar in their world views and education.

In contrast, the sudden rejection and dismissal of the communist worldviews and cognitive schemes in Russia produced an intellectual pluralism. This may have facilitated the emergence of various views among network ties. There is no dominant networking principle that structures syyazi networks and, therefore, Russian 
networks are composed of people who differ in their ascribed and achieved attributes, including their specialization in education. The less cognitive pressure to internalize and absorb the views of other contacts in the network produces the heterogeneity in Russian networks.

Hypothesis 3: Network homogeneity (e.g., educational specialization) of Chinese entrepreneurs is greater than that of Russian entrepreneurs.

The Chinese guanxi and Russian syyazi may differ also in terms of tie strength defined as the extent to which two persons are close, talk frequently and perceive that their relationships are strong. Relationships in Chinese networks require frequent interactions and intense efforts to maintain; and they are costly to maintain in terms of time, resources and commitment. The frequent interaction and mutual investment in the relationship produce stronger network ties in China, relative to those in Russia. The multiplex nature of Chinese ties, i.e., a single relationship fulfils various functions including access to information and resources, emotional support and political protection, further add to the development of strong relationships among network ties.

The Chinese and Russian triads (three-person relationships) differ in terms of mutual expectations, social control mechanisms and symbolic aspects of interactions. Social sanctions are more effective in Chinese triads because 'face' serves as a social currency that has a definite value. In addition, Chinese are likely to have higher expectations and show more conformist behaviours in triple relationships for cultural reasons. The Russian concept of reciprocity in triads is simpler, less universal and often ignored in relationships. Therefore, Russians have to rely more on 'mechanical' monitoring techniques; this leads to higher cost in terms of reinforcement of social obligations.

In this study, I focus on the relationship between the venture capitalist and his or her referee. A referee is the third party who recommends an entrepreneur as a potential equity capital receiver to a venture capitalist (Batjargal and Liu, 2004). The relationship with the referee can influence the venture capitalist's response (positively or negatively) to the recommendation. Venture capitalist and referee tie is likely to be stronger in China because Chinese referees prefer to send referrals to those investors with whom they have stronger relationships (Batjargal and Liu, 2004). In this way, referees serve as selectors of potential venture capital receivers. In addition, Chinese venture capitalists expect to receive recommendations from those referees with whom they have strong ties because the strong-tie referees will recommend only those entrepreneurs whose firms have high growth potential and who are reliable, motivated and skilled. In contrast, the venture capitalist-referee tie is weaker in Russia than in China because if a Russian referee regards a venture as high potential, he/she is likely to issue recommendations irrelevant of the tie strength between $\mathrm{VG}$ and referee. Further, Russian investors are likely to expect to receive recommendations from both strong and weak ties. 
Hypothesis 4: Venture capitalist-referee tie is stronger in China than in Russia.

I further propose that the degree of interpersonal trust in the network would be different between China and Russia. Interpersonal trust is 'a particular level of subjective probability with which an agent assesses that another agent or group of agents will perform a particular action, both before he can monitor such action (or independently of his capacity ever to be able to monitor it) and in a context in which it affects his own action' (Gambetta, 1990, p. 217). The institutional stability in China provides favourable conditions for a higher level of trustworthiness of the Chinese compared to the Russians (Hitt et al., 2004). The Chinese do trust their family members and close friends but distrust those whom they do not know (Child and Mollering, 2003; Redding, 1990). Consistent with this observation, the World Bank survey found that more than fifty percent of Chinese entrepreneurs fully agreed with the statement 'most people can be trusted', whereas only sixteen percent of the Russians fully agreed with the same statement (Djankov et al., 2006). While the Chinese have greater trust in their family members, friends and colleagues, they are less trustful of people from other towns or foreigners than are the Russians (Djankov et al., 2006).

The Chinese generally trust those who have been recommended to them by a trustworthy source - a family member or close friend (Lin, 2001). In this way, interpersonal trust is more 'transferable' in China. In addition, the Chinese are more skillful in establishing well-defined exchange rules and punishing those who violate exchange norms.

The Russians do trust their family members but clan-type relationships (where non-family members become in-group members) do not exist in Russia. Unlike the Chinese, the Russians are less trustful of third parties even if a trusted intermediary has recommended that person (Petrovskii, 1991). The Russian practice 'I am from Alexandr Alexandrovich', a common phrase meaning a referral, is used to stress instrumental aspects of relationships rather than cultivation of interpersonal trust. Russians prefer to establish direct personal relationships since triad ties are perceived to be risky in the chaotic environment. Direct communications are more effective for trust building.

\section{Hypothesis 5: Interpersonal trust in the referee is greater in China than in Russia.}

\section{METHODS}

\section{Sample and Data of Software Entrepreneurs}

My assistants and I created sample lists of software ventures in Beijing and Moscow by using telephone directories, government sources, computerized databases of enterprises and Internet resources. We used the following four criteria to select new software ventures: (i) venture must be six years old or younger in 2003, i.e., 
established in 1997 and afterwards; (ii) venture must be registered as a dedicated software firm where the main business is software; (iii) the head-office is located in Beijing or Moscow; and (iv) the venture should be fully owned by domestic shareholders.

In Moscow, we created and contacted a list of 111 new, dedicated and domestic software ventures. The response rate for the Russian sample is 74 percent or 82 entrepreneurs. In Beijing, we created and contacted a list of 172 ventures. The response rate for the Chinese sample is 45 percent or 77 entrepreneurs. Of the 159 total sample, 118 were CEOs and 41 were chief technology officers (CTO).

Due to the lower response rate in China (45 percent) relative to that in Russia (74 percent), we conducted the ANOVA tests on firm age and location (whether the firm was in Zhongguancun, the high-tech district in Western Beijing) between the respondents (those interviewed) and non-respondents (those who refused the interview) for the Chinese sample. I found that location difference was not statistically significant whereas younger firms were more likely to decline.

I collected the data using structured telephone interviews. The questionnaire was designed initially in English. Teams of Chinese and Russian management professors translated the questionnaire. Different Chinese and Russian scholars did back translation and cross-checking. Two research assistants and I conducted interviews in Moscow and the team of six research assistants carried out interviews in Beijing.

\section{Sample and Data of Venture Capitalists}

I used telephone directories, government brochures, databases of financial services firms and Internet sources to create an initial sample. The sampling criteria were the following: (i) the firm should be registered as a private equity firm; (ii) the firm should be owned fully by domestic shareholders and partners; and (iii) firms should operate in Beijing (for Chinese firms) or Moscow (for Russian firms).

In Moscow, I identified 23 domestic private equity firms and conducted structured telephone interviews with CEOs and lead fund managers of 15 venture capital (VC) firms in July-August 2003. In Beijing, we created a list of 117 domestic VC firms and interviewed 22 CEOs and lead fund managers in SeptemberOctober 2003. In all, we interviewed $37 \mathrm{CEOs}$ and lead fund managers in the two cities. We interviewed one respondent per VC firm. Ninety percent of the respondents were CEOs and ten percent were lead fund managers. We interviewed lead fund managers in cases when CEOs were not available.

We asked each respondent to select the last two positive investment decisions (firm decided to invest) based upon recommendation of third parties (referees), and the last two negative investment decisions (firm decided not to invest) despite recommendations of third parties. Thus, we collected information on a maximum of four investment decisions from each respondent. Some respondents reported fewer than four decisions. In total, we collected information on 124 investment 
decisions, 62 positive and 62 negative. The goal is not to contrast positive with negative decisions, but to ensure variance in the decisions.

The sampling of investment decisions is retrospectively matched sampling because positive venture capital decisions are rare events. This method has been used fruitfully in venture capital research (Sorenson and Stuart, 2001). The use of a matched sample does not accurately account for independence across cases because each firm enters the analysis several times. One way to deal with this problem is to create firm dummies. This would require creating 37 venture capital firm dummies. We did not pursue this procedure because we wished to preserve statistical power. The information about referees was collected from the respondents. We asked each venture capitalist to identify a referee for each decision that the venture capitalist (VC) made. Thus, each VG named four referees for four decisions. In this way, the number of decisions equals the number of referees. All investment decisions involved referees because I examine the role of referees in investment decisions.

\section{Measures}

Independent variable. The predictor variable is country dummy (Chinese $=$ ' 1 ', and Russian $={ }^{\prime} 0$ ').

Dependent variables. Data on network structure were collected by the method of name generators (Burt, 1992; Marsden, 1990). The questionnaire contained one name generator and one name interpreter question. The name generator question is: 'The next questions are about those with whom you often discuss issues related to software programming and design. Please name those persons with whom you have discussed software programming issues over the last six months'. The respondents were restricted to providing a maximum of eight names. The network content is the discussion network about software programming and design. This network may be regarded as a type of professional network of entrepreneurs. The name interpreter was alter (or the network tie) education (a BA degree in engineering, science and arts/humanities). The question that captured network density is: 'The next question is to describe the strength of relations between listed people. You do this by circling codes in the matrix below. This is a complex question, but it is essential to measuring of social networks - and answering the question is a simple task when taken one column at a time. Begin with the first person listed. Relations with the first person are listed in the third column. Indicate his or her relationship with the person in each row in one of three ways: Circle $\mathrm{E}$ if there is an "especially close" relation between the row person and the first person. Circle $\mathrm{D}$ if the row person and first person are "distant" in the sense that they rarely work together, are total strangers as far as you know, or do not enjoy one another's company. Leave E or D blank to indicate that the two people are "neither distant nor especially close" ' (Burt, 1992). 
Network size is the number of contacts named. Network density is measured as the percentage of 'especially close' and 'neither distant nor especially close' relationships within the total number of possible relationships among alters (Marsden, 1990). Education homogeneity is measured as the inverse of the Index of Qualitative Variation (IQV) (Agresti and Agresti, 1978). The IQV indicates the dispersion of the alters over three nominal categories of education, i.e., engineering, science and arts/humanities. ${ }^{[1]}$ For example, if the IQV is 0.45 , education homogeneity is $(1-0.45=0.55$. This variable indicates the extent to which alters are similar in their education.

Venture capitalist-referee tie strength was measured by two items: 'How close are you with each third-party (referee)'; 'On average, how often do you talk to each third-party (referee)' (Cronbach's alpha is 0.81 ). This is a standard measurement for tie strength (Marsden, 1990). The interviewees responded to two four-point Likert scale items. The first item was measured as especially close (4), close (3), less than close (2) and distant (1). The second item was measured as daily (4), weekly (3), monthly (2) and less often (1). The mean of two items was used as the scale score.

Interpersonal trust in the referee was measured by the following item: 'What extent do you (venture capitalist) trust the third-party (referee)?' The distribution value was a five-point Likert scale from do not trust (1) to trust very much (5).

In summary, data for three of the five dependent variables were obtained from the entrepreneur: network size, network density and network education homogeneity. Data for two dependent variables were obtained from the venture capitalist: tie strength with the referee and interpersonal trust in the referee.

Control variables. I include several control variables that are typical in entrepreneurship and venture capital research (Batjargal and Liu, 2004). Firm age (Software and $V C$ ) is the number of years a firm had been in existence. Firm size (Software and VC) is measured by the number of full-time employees at the time of survey. Venture capital (Software) is a binary variable of 1 if private equity was raised and 0 otherwise. Ownership (Software) is a binary variable of 1 if the major shareholder is the respondent and 0 otherwise. IT industry $(V C)$ is a binary variable of 1 if the equity receiver firm is in IT and zero otherwise. State ownership $(V C)$ is a binary variable of 1 if state is a shareholder and zero otherwise. Venture capitalist experience is measured in years of working as investor. Investments under management is the number of investments under the direct management of the investor.

Data validation. In order to check data quality, we telephoned a subset of the entrepreneurs. During the interviews with software entrepreneurs, we asked for phone numbers of one of the contacts listed. In all, 41 Chinese respondents and 28 Russian respondents provided phone numbers. By selecting every second name on the list of 41 Chinese contacts, and every second and third on the list of 28 Russian contacts, we contacted 20 Chinese and 20 Russian alters, and asked several questions. 
We asked whether the contact's BA education was in engineering, science or arts/humanities. Nineteen of the 20 Chinese alters (95 percent) and 18 of the 20 Russian contacts (90 percent) gave the same answers as the respondents. Therefore, the data on the education variable is reliable. We asked each contact to describe her/his relationship with the person next on the entrepreneur's list in terms of 'especially close', 'distant' and 'neither especially close nor distant'. The answers of 20 Chinese contacts (100 percent) and seventeen Russian contacts (85 percent) were the same with the entrepreneurs' answers. This indicates that the data for network density is reliable.

During the interviews with venture capitalists, we asked for the phone numbers of one referee. In all, we obtained the phone numbers of 12 Chinese referees, and eight Russian referees. We made phone calls to these referees.

We asked these referees several questions to verify the responses of the venture capitalists. We asked the question: 'How close are you to the venture capitalist?' All 12 Chinese referees and six of the eight Russian referees provided the same answers as the venture capitalists. We asked the question: 'To what extent do you trust the venture capitalist?' We found that the answers of 11 Chinese referees and seven Russian referees to be the same as those we collected from the venture capitalists. As a whole, these findings suggest that our data on venture capitalists' perceptions seem to be reliable.

\section{RESULTS}

Table 1 contains the means, standard deviations and Pearson's correlations for all the variables for the combined sample of the Chinese and Russian software entrepreneurs $(\mathrm{N}=159)$. Table 2 presents the descriptive statistics and Pearson's correlations for the combined sample of Chinese and Russian venture capitalists (the number of investment decisions is 124).

Table 3 reports the ANOva results comparing the values on all the variables for the Chinese and Russian software entrepreneurs. Table 4 shows the ANOva results on all the variables for the Chinese and Russian venture capitalists. The findings in these tables reveal that professional networks of the Chinese entrepreneurs are smaller, denser and more homogeneous. Venture capitalist-referee tie is stronger and interpersonal trust is higher in China than in Russia. The results on these univariate comparisons are consistent with the hypotheses.

In Table 5, I present the results of the multiple regression analysis predicting network structure of Chinese and Russian entrepreneurs. Model 1 reveals that network size of the Chinese entrepreneurs is smaller $(\mathrm{B}=-0.32, \mathrm{p}<0.001)$. Hypothesis 1 predicting a smaller network size for the Chinese is confirmed. Model 2 suggests that the professional networks of the Chinese entrepreneurs are denser $(\mathbf{B}=0.37$, $\mathrm{p}<0.0010$ ). Hypothesis 2 proposing more cohesive networks for the Chinese is supported. Model 3 illustrates that guanxi networks are more homogeneous in terms 


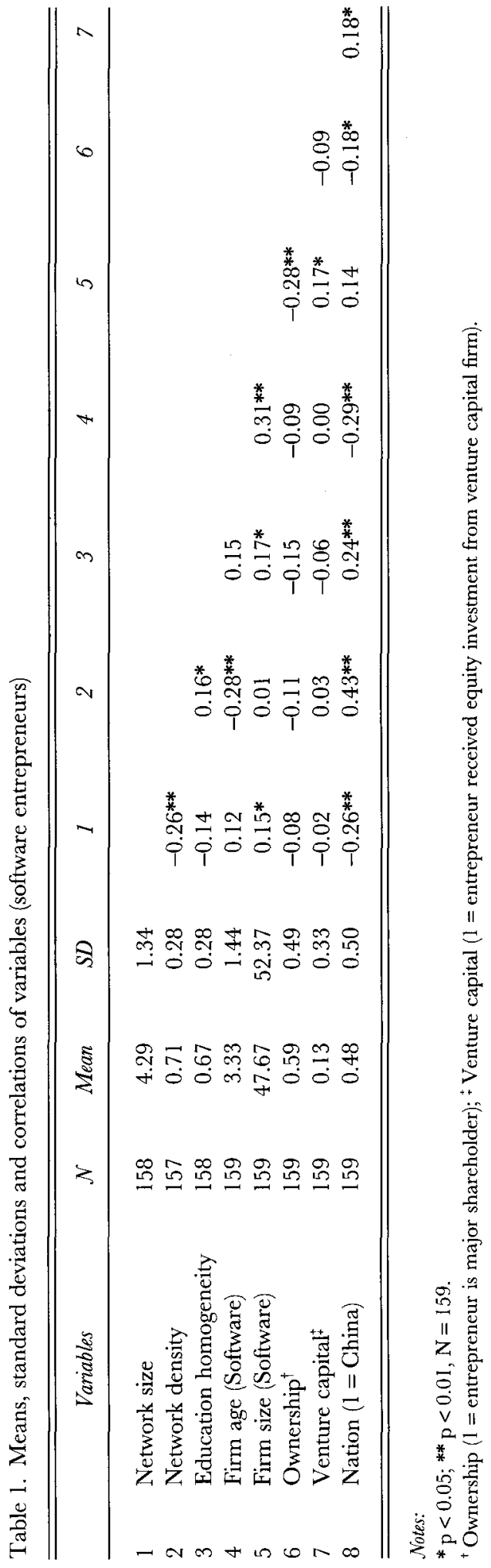


Comparative Social Capital

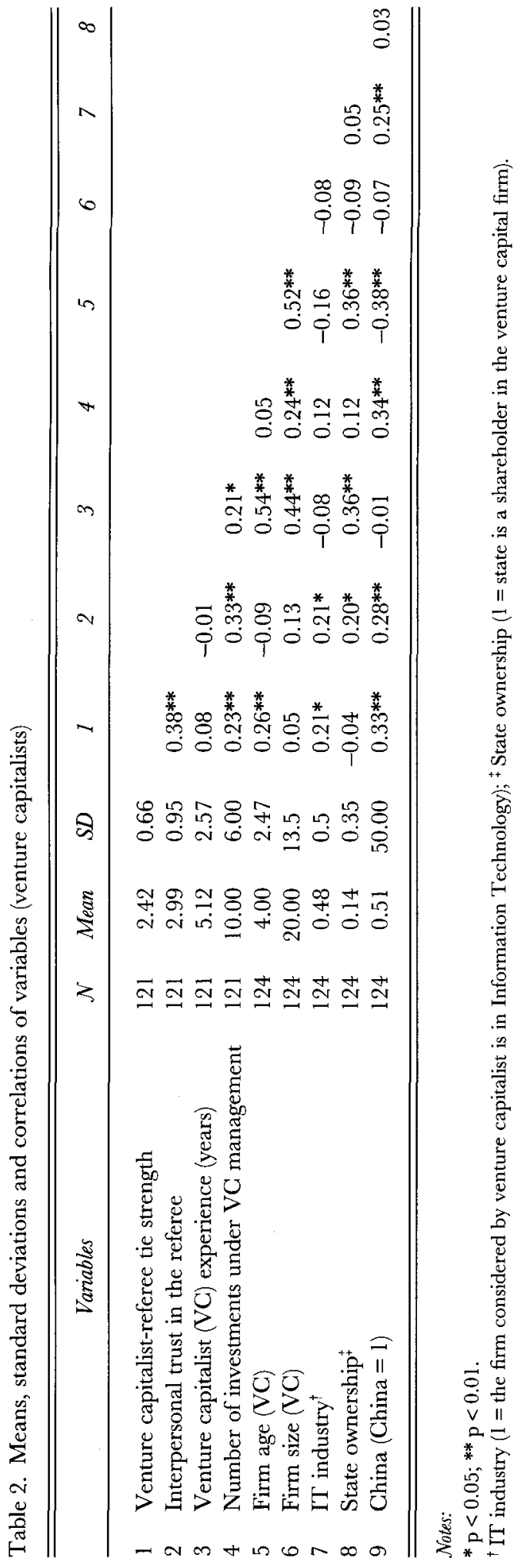


Table 3. Descriptive statistics and ANova (software entrepreneurs)

\begin{tabular}{|c|c|c|c|c|c|c|c|c|}
\hline & & \multicolumn{3}{|c|}{ China } & \multicolumn{3}{|c|}{ Russia } & \multirow{2}{*}{$\frac{\text { ANOVA }}{F}$} \\
\hline & & $\mathcal{N}$ & Mean & $S D$ & $\mathcal{N}$ & Mean & $S D$ & \\
\hline 1 & Network size & 76 & 3.92 & 1.45 & 82 & 4.63 & 1.13 & $11.82^{* * *}$ \\
\hline 2 & Network density & 75 & 0.84 & 0.27 & 82 & 0.59 & 0.23 & $35.81^{* * *}$ \\
\hline 3 & Network education homogeneity & 76 & 0.74 & 0.33 & 82 & 0.60 & 0.21 & $9.70^{* *}$ \\
\hline 4 & Firm age (Software) & 77 & 2.89 & 1.32 & 82 & 3.74 & 1.43 & $15.29 * * *$ \\
\hline 5 & Firm size (Software) & 77 & 55.48 & 54.67 & 82 & 40.34 & 49.33 & $3.36^{\circ}$ \\
\hline 6 & Ownership & 77 & 0.50 & 0.50 & 82 & 0.68 & 0.46 & $5.24^{*}$ \\
\hline 7 & Venture capital & 77 & 0.19 & 0.39 & 82 & 0.07 & 0.26 & $5.22 *$ \\
\hline
\end{tabular}

Note: ${ }^{\Uparrow} \mathrm{p}<0.1 ;{ }^{*} \mathrm{p}<0.05 ;{ }^{* *} \mathrm{p}<0.01 ;{ }^{* * *} \mathrm{p}<0.001$.

Table 4. Descriptive statistics and ANOva (venture capitalists)

\begin{tabular}{|c|c|c|c|c|c|c|c|c|}
\hline & & \multicolumn{3}{|c|}{ China } & \multicolumn{3}{|c|}{ Russia } & \multirow{2}{*}{$\frac{\text { ANOVA }}{F}$} \\
\hline & & $\mathcal{N}$ & Mean & $S D$ & $\mathcal{N}$ & Mean & $S D$ & \\
\hline 1 & Venture capitalist-referee tie strength & 61 & 2.63 & 0.63 & 60 & 2.20 & 0.62 & $14.57^{* * *}$ \\
\hline 2 & Interpersonal trust in the referee & 61 & 3.26 & 1.11 & 60 & 2.71 & 0.66 & $10.71^{* * *}$ \\
\hline 3 & Venture capitalist experience & 64 & 4.86 & 2.61 & 60 & 5.40 & 2.51 & 1.33 \\
\hline 4 & Investments under management & 64 & 12 & 8 & 60 & 8 & 2 & $16.36^{* * *}$ \\
\hline 5 & Firm age $(\mathrm{VC})$ & 64 & 3.12 & 1.06 & 60 & 5 & 3.12 & $20.52^{* * *}$ \\
\hline 6 & Firm size (VC) & 64 & 19 & 9 & 60 & 20 & 16 & 0.6 \\
\hline 7 & IT industry & 64 & 0.60 & 0.49 & 60 & 0.35 & 0.48 & $8.8^{* *}$ \\
\hline 8 & State ownership & 64 & 0.15 & 0.36 & 60 & 0.13 & 0.34 & 0.12 \\
\hline
\end{tabular}

Note: ${ }^{*} \mathrm{p}<0.05 ; * * \mathrm{p}<0.01 ; * * * \mathrm{p}<0.001$.

of educational specializations $(\mathrm{B}=0.31, \mathrm{p}<0.001)$. Hypothesis 3 proposing greater network homogeneity for the Chinese entrepreneurs is supported.

Table 6 reveals the multiple regression results for the hypotheses on the venture capitalist-referee tie strength and interpersonal trust with referee tie. Model 1 suggests that venture capitalist-referee tie is stronger in China $(B=0.20, p<0.05)$. Hypothesis 4 is confirmed. Model 2 indicates that interpersonal trust with referee is marginally greater in China $(\mathrm{B}=0.06, \mathrm{p}<0.10)$. Hypothesis 5 is marginally supported.

\section{DISCUSSION}

The findings suggest that the professional networks of Chinese entrepreneurs are smaller, denser and more homogeneous in terms of educational background compared with the networks of Russian entrepreneurs. This may be due to the 
Table 5. Regression analysis predicting networks of Chinese and Russian software entrepreneurs

\begin{tabular}{|c|c|c|c|}
\hline & Network size & Network density & Education homogeneity \\
\hline & Model 1 & Model 2 & Model 3 \\
\hline Firm age (Software) & -0.04 & $-0.18^{*}$ & $0.22 *$ \\
\hline Firm size (Software) & $0.19^{*}$ & -0.01 & 0.06 \\
\hline Ownership & -0.09 & -0.06 & -0.07 \\
\hline Venture capital & -0.01 & -0.03 & -0.13 \\
\hline China & $-0.32^{* * * *}$ & $0.37^{* * *}$ & $0.31^{* * * *}$ \\
\hline Model $F$ & $4.09^{* *}$ & $8.55^{* * *}$ & $4.89^{* * *}$ \\
\hline Adjusted $R$ square & 0.09 & 0.19 & 0.11 \\
\hline
\end{tabular}

Note: ${ }^{*} \mathrm{p}<0.05 ; * * \mathrm{p}<0.01 ; * * * \mathrm{p}<0.001, \mathrm{~N}=159$.

Table 6. Regression analysis predicting networks of Chinese and Russian venture capitalists

\begin{tabular}{lccc}
\hline & Venture capitalist-referee tie strength & & Interpersonal trust in the referee \\
\cline { 2 - 3 } & Model 1 & Model 2 \\
\hline Firm age (VC) & -0.20 & $-0.37^{*}$ \\
Firm size (VC) & $0.44^{* * *}$ & $0.32^{*}$ \\
IT industry & $0.14^{\pi}$ & 0.10 \\
State ownership & 0.06 & 0.34 \\
Investments under management & 0.03 & $0.19^{*}$ \\
China & $0.20^{*}$ & $0.06^{\pi}$ \\
Model $F$ & $6.78^{* * *}$ & $6.59^{* * *}$ \\
Adjusted $R$ square & 0.22 & 0.21 \\
\hline \hline
\end{tabular}

Note: ${ }^{\top} \mathrm{p}<0.1 ;{ }^{*} \mathrm{p}<0.05 ;{ }^{* *} \mathrm{p}<0.01 ;{ }^{* * *} \mathrm{p}<0.001, \mathrm{~N}=124$.

institutional and cultural differences between the two countries. The hybrid institutional framework in China seems to affect the dynamics of the guanxi networks in contradictory ways. On the one hand, it promotes relational stability and reduces social uncertainties, which are reflected in smaller, more integrated, and homogeneous networks. In contrast, these closed, dense and homogenous networks may also hinder network restructuring, membership renewal and resource enrichment.

The institutional chaos in Russia seems to have generated social dislocation and the loss of old ties. This may have forced Russian entrepreneurs to build new networks that are larger, less cohesive and more heterogeneous.

The Chinese preference for smaller and close-knit networks also may be due to the cultural features such as particularism and groupism. Chinese entrepreneurs actively promote mutual dependence and interconnectedness in order to eliminate any gaps in their networks. Network transitivity is greater in China and, therefore, 
the guanxi cliques have clearly defined boundaries for members and non-members. In this sense, members of a particular guanxi network have strong identities and high expectations as a part of a 'clan'. The guanxi networks are more homogeneous in terms of knowledge, ideas and worldviews. This feature promotes intellectual solidarity and social harmony among network members. The high density and homogeneity makes guanxi networks less inclusive and, therefore, those who are perceived as outsiders, and those who have different views, are likely to be excluded from important guanxi deals. This network closure offers certain advantages as well as disadvantages for its members. For example, Batjargal (2004) found that dense and homogeneous networks of entrepreneurs have positive effects on product development and revenue growth of new firms at early stages because of trust, cooperation and solidarity benefits. However, tight and uniformed networks may turn into liabilities by blocking information and resource flows at later stages of venture development (Batjargal, 2004; Fu et al., 2006).

In contrast, the Russian networks are composed of weaker ties and members who differ in their mindsets and knowledge patterns. In this sense, the szyazi networks are more open and absorptive. Russians seem to benefit more from networks rich in structural holes that expose them to diverse knowledge, opportunities and resources. The downsides of such networks are greater membership turnover, unstable relationships and high monitoring costs.

The dyadic ties are stronger and interpersonal trust, measured from the venture capitalist's perspective, is greater in China. The negotiated institutional changes enabled the Chinese venture capitalists (and most likely entrepreneurs also) to keep intact for years the task-related ties from their old organizations, e.g., the government bureaucracy. This is reflected in greater tie strength and trust. The cadres from the old organizations were transferred to the new institutions step by step and, therefore, networks were not disrupted. The institutional continuity generated a sense of certainty and confidence among the Chinese that facilitated cooperative and trustworthy behaviour of actors. In a relatively stable environment, contacts provide useful information and resources on a regular basis. This reduces the entrepreneurs' motivations to restructure their networks.

Again, culture offers a more convincing explanation of the prevalence of trust in networks. The core elements in Chinese thinking - the doctrine of the middle and the balance between yin and yang - encourage Chinese not to take drastic actions regarding established relationships. This may lead to greater interpersonal affection and mutual trust. The Confucian emphasis on social harmony and conflict avoidance facilitates trust building among members of a guanxi network over time. The groupist mindsets and a strong sense of belonging lead to frequent and substantive communications. This is conducive to greater trust and lasting relationships. A Chinese person defines her identity through relationships with her family and intimate friends, who are trusted and respected. Further, there are numerous guanxi methods that people use to cultivate strong ties (Yang, 1994). 
Thus, frequent interactions, multi-content relationships, informal norms and mutual expectations make guanxi ties stronger.

The Russian dyadic ties are weaker, and there is less trust embedded in them. The unstable social and institutional environment, where the old norms were discredited and the new rules are ignored, and the more individualistic Russian cultural propensities may partially explain this finding (Ralston et al., 1997).

The evolutionary transformation in China, i.e., the parallel process of the emergence of new rules and survival of the old organizations, and the core cultural values of the Chinese provide greater stability, continuity and harmony which are reflected in smaller, more cohesive and homogeneous networks, and stronger and trusted dyadic relationships. The revolutionary nature of the Russian reforms, i.e., the simultaneous process of violent destruction of the old institutions and inhibited emergence of new rules and regulations, and the core Russian cultural characteristics generated institutional and cultural environments that are conducive to larger, less integrated and heterogeneous networks, and weaker and less trusted ties. Thus, the institutional and cultural differences of the two nations are reflected in varying network structures and relations.

\section{Contributions and Limitations}

This study may make several contributions. First, the finding that local institutions and cultures may affect social capital in interactive ways is a relatively new finding both in institutional theory and cultural paradigm. Second, this study is one of the first systematic studies that examined networks of entrepreneurs and venture capitalists as dependent variables and, therefore, the paper is a contribution to the growing literature on entrepreneurial networks. Third, by comparing and contrasting Chinese guanxi and Russian syyazi networks, I make a contribution to the comparative management literature on China and Russia.

This article has several limitations that should be acknowledged. I did not measure institutions and national cultures directly, instead I used China and Russia country dummy variables. This introduces possibilities of alternative explanations. For example, the economic conditions and population density in the two countries also are 'captured' by country dummies and, therefore, their effects on networks can't be ruled out. This study examines professional networks of software entrepreneurs. Therefore, there is an issue of generalizability of the findings to other informal networks, such as friendship or community networks. Further, this study focused on one network content - technical advice and, therefore, one should be cautious of over-generalization of the results. The samples are relatively small and the sampling of venture capitalists is neither complete nor random. There is an issue of the potential non-independence of observations. I used network measurements developed in the West for measuring Chinese guanxi and Russian syyazi. In this way, I may have overlooked unique indigenous features of guanxi and syyazi. Last but not least, 
the study did not include performance outcomes of different network structures in Russia and China, limiting both the theoretical and practical contribution.

\section{Implications for Future Research}

I suggest several implications for further research. The concept 'comparative social capital' should be further refined and operationalized so that valid measurement can be developed. Comparative analysis of guanxi and svyazinetworks may be conducted at inter-organizational level. For example, one could examine how inter-firm alliances differ in the two countries, and what are the implications of these differences for firm performance. Another interesting and important topic for further research is comparative analysis of social capital in country contexts beyond China and Russia. For example, how do Japanese kankei and Korean inmak networks differ, or how do Chinese guanxi and Indian sambandh or jaan-pehchaan (in Hindi) networks differ, and what implications do they have for business performance.

Networks are functional structures that serve a purpose in their own cultural contexts. Therefore, the effects of similar network patterns, e.g., networks rich in structural holes, on outcome variables are likely to be different depending on cultural context. For example, in more individualistic societies (e.g., the USA), structural holes may be beneficial to people's careers (Burt, 1992). However, in the high-commitment and collectivistic cultures (e.g., China), structural holes may be harmful to persons' careers (Xiao and Tsui, 2007). Therefore, the contingency value of social networks in cross-cultural contexts should be studied.

Networks as outcomes of everyday interactions and socializations are influenced by demographic characteristics of individuals. Therefore, how gender, education, age, ethnicity, race and occupation affect network structures in different cultural contexts is an important dimension of network research. Cultural values, for example feminine vs. masculine values, might influence network patterns. People in masculine cultures may network for more utilitarian purposes, whereas people in feminine cultures may network more for the sake of relationships. Demographic variables, cultural values and networks are likely to affect outcome variables in important ways. Therefore, these effects should be studied.

Institutional frameworks, i.e., laws, courts, administrative structures and taxation systems, are likely to have direct impacts on network patterns. Certain types of institutional arrangements may be associated with particular patterns of networks. When and how networks compensate for dysfunctional or non-existent institutions, when and how effective and legitimate institutions eliminate corrupt and semi-legal networks and clans, and what implications they have for firm performance are important directions for future research on comparative networks.

Cognitive variables, for example time perception or emotional intelligence, may affect networking processes. Therefore, comparative study of cognitions and networking processes in different institutional and cultural contexts is a promising 
theme in network research. Physical variables such as height, weight and perceived looks are likely to affect social interaction processes. Therefore, how physical characteristics of individuals affect networking outcomes, and what implications they have for career success and entrepreneurial performance, are interesting directions in comparative network research.

Finally, the negative aspects of networks, for example, favouritism, nepotism and corruption in Chinese guanxi networks, and manipulation, violence and criminal elements in Russian syyazi networks, are important themes to be studied in future research.

\section{CONGLUSION}

The gradual institutionalization and Confucian cultural values in China make guanxi networks smaller, denser and homogeneous, and dyadic ties stronger and trusting. The rapid deinstitutionalization and Orthodox Christian cultural values in Russia make syyazi networks larger, disperse and heterogeneous, and dyadic ties weaker and less trusting. The study suggests that actors build and mobilize networks in concrete institutional and cultural environments, and these contexts have significant impacts on networks.

\section{NOTES}

I would like to thank my research assistants who collected data in Beijing and Moscow. I am grateful to Yanjie Bian, Anne Tsui and two anonymous reviewers for their valuable comments and suggestions. I thank Debmalya Mukherjee for the expression 'connections' in the Hindi language in India.

[1] $I=[k /(k-1)]\left(1-\sum_{i=1}^{k} \hat{p}_{i}^{2}\right)$ The Index of qualitative variation: $k$ is the number of categories; $\hat{p}_{i}^{2}$ is the sample proportions of observations in these categories.

\section{REFERENGES}

Agresti, A., \& Agresti, B. 1978. Statistical analysis of qualitative variation. Sociological Methodology, 9: 204-237.

Batjargal, B. 2001. Effects of networks on entrepreneurial performance in a transition economy: The case of Russia. In P. Reynolds et al. (Eds.), Frontiers of entrepreneurship research: 97-1 10. Cambridge, Mass: Babson College.

Batjargal, B. 2003a. Internet entrepreneurship in an emerging market: Networks and performance of Internet startups. In D. H. Nagao (Ed.), Best paper proceedings of the Annual Meeting of the Academy of Management (CD). Boulder, CO: The Academy of Management.

Batjargal, B. 2003b. Social capital and entrepreneurial performance in Russia: A longitudinal study. Organization Studies, 24: 535-556.

Batjargal, B. 2004. Software entrepreneurship: Knowledge networks and performance of software ventures in emerging economies. Working paper, \# 751. Ann Arbor, Mich: William Davidson Institute, University of Michigan Business School.

Batjargal, B. 2005. Entrepreneurial versatility, resources and firm performance in Russia: A panel study. International Journal of Entrepreneurship and Innovation Management, 5(3/4): 284-287. 
Batjargal, B. 2006. The dynamics of entrepreneurial networks in a transition economy: The case of Russia. Entrepreneurship and Regional Development, 18(4): 305-320.

Batjargal, B. 2007a. Network triads: Transitivity, referral, and venture capital decisions in China and Russia. Jourmal of International Business Studies (in press).

Batjargal, B. 2007b. Internet entrepreneurship: Social capital, human capital, and performance of Internet ventures in China. Research Policy, 36: 605-618.

Batjargal, B., \& Liu, M. 2004. Entrepreneurs' access to private equity in China: The role of social capital. Organization Science, 15(2): 159-172.

Bian, Y. 1997. Bringing strong ties back in: Indirect ties, network bridges, and job searches in China. American Sociological Review, 62: 366-385.

Blanchard, O., \& Kremer, M. 1997. Disorganization. The Quarterly Jourmal of Economics, 112(4): 1091-1126.

Borgatti, S., \& Cross, R. 2003. A relational view of information seeking and learning in social networks. Management Science, 49: 432-445.

Bourdieu, P. 1986. The forms of capital. In J. Richardson (Ed.), Handbook of Theory and Research for the Sociology of Education: 241-258. New York: Greenwood.

Brass, D. 1985. Men's and women's networks: A study of interaction patterns and influence in an organization. Academy of Management Joumal, 28: 327-343.

Brass, D., Galaskiewicz, J., Greve, H., \& Tsai, W. 2004. Taking stock of networks and organizations: A multilevel perspective. Academy of Management Journal, 47(6): 795-817.

Burt, R. 1992. Structural Holes, the social structure of competition. Cambridge, Mass: Harvard University Press.

Burt, R., Hogarth, R., \& Michaud, C. 2000. The social capital of French and American managers. Organization Science, 11: 123-147.

Child, J., \& Mollering, G. 2003. Contextual confidence and active trust development in the Chinese business environment. Organization Science, 14(1): 69-80.

Colyvas, J., \& Powell, W. 2006. Roads to institutionalization: The remaking of boundaries between public and private science. In B. Staw (Ed.), Research in organizational behavoir: Vol. 27, 305-353. JAI Press.

Dai, J. 2002. Newly born private enterprise owners in China. Social Sciences in China, 23: $124-134$.

Djankov, S., Qian, Y., Roland, G., \& Zhuravskaya, E. 2006. Entrepreneurship in China and Russia compared. Journal of European Economic Association, 4(2-3): 352-365.

Droege, S., \& Johnson, N. 2007. Broken rules and constrained confusion: Toward a theory of meso-institutions. Management and Organization Revieze, 3(1): 81-104.

Efremova, T. 2000. Novyi Slovar' Russkogo Yazyka, tolkovo-slovoobrazitel'nyi, 2. Moscow: Russkii Yazyk Press.

Farh, L., Tsui, A., Xin, K., \& Cheng, B. 1998. The influence of relational demography and guanxi: The Chinese case. Organization Science, 9(4): 471-488.

Fu, P., Tsui, A., \& Dess, G. 2006. The dynamics of guanxi in Chinese high tech firms: Implications for knowledge management and decision-making. Management International Review, 46(3): $277-305$.

Gambetta, D. 1990. Can we trust trust? In D. Gambetta (Ed.), Trust: Making and breaking cooperative relations: 213-237. Oxford: Blackwell Publishers.

Graham, L., \& Kantor, J. 2006. A Comparison of two cultural approaches to mathematics, France and Russia, 1890-1930. Isis, 97: 56-74.

Guseva, A., \& Rona-Tas, A. 2001. Uncertainty, risk, and trust: Russian and American credit card markets compared. American Sociological Revieze, 66: 623-646.

Hitt, M., Ahlstrom, D., Dacin, T., Levitas, E., \& Svobodina, L. 2004. The institutional effects on strategic alliance partner selection in transition economies: China versus Russia. Organization Science, 15(2): 173-185.

Hofstede, G. 1984. The cultural relativity of the quality of life concept. The Academy of Management Review, 9(3): 389-398.

King, A. 1991. Kuan-hsi and network building: A sociological interpretation. Daedalus, 120(2): 63-84.

Ledeneva, A. 1998. Russia's economy of favors: Blat, networking and informal exchange. Cambridge: Cambridge University Press. 
Lin, N. 2001. Guanxi: A conceptual analysis. In A. So, N. Lin, \& D. Poston (Eds.), The Chinese triangle of Mainland China, Taizuan, and Hong Kong, comparative institutional analysis: 153-166. London: Greenwood Press.

Marsden, P. 1990. Network data and measurement. Annual Revieze of Sociology, 16: 435-463.

Nee, V. 1992. Organizational dynamics of market transition: Hybrid forms, property rights, and mixed economy in China. Administrative Science Quarterly, 37: 1-27.

Oliver, C. 1992. The Antecendents of deinstitutionalization. Organization Studies, 13(4): 563-588.

Park, S., \& Luo, Y. 2001. Guanxi and organizational dynamics: Organizational networking in Chinese firms. Strategic Management Journal, 22: 455-477.

Petrovskii, A. 1991. Trekhfaktornaya model 'znachimogo drugogo'. Voprosy Psikhologii, 1: 7-18.

Ralston, D., Holt, D., Terpstra, R., \& Kai-Cheng, Y. 1997. The impact of national culture and economic ideology on managerial work values: A study of the United States, Russia, Japan, and China.Journal of International Business Studies, 1: 177-207.

Redding, G. 1990. The spirit of Chinese capitalism. New York: Walter De Gruyter.

Scott, R. 2000. The changing world of Chinese enterprise: An institutional perspective. In J. T. Li, A. Tsui, \& E. Weldon (Eds.), Management and organizations in the Chinese context: 59-78. New York: St. Martin's Press.

Scott, R. 2001. Institutions and organizations. London: Sage Publications.

Sedaitis, J. 1998. The alliances of spin-offs versus start-ups: Social ties in the genesis of post-Soviet alliances. Organization Science, 9(3): 368-381.

Segal, A. 2003. Digital dragon: High technology enterprises in China. Ithaca, NY: Cornell University Press.

Shleifer, A. 2005. A normal country, Russia after communism. Cambridge, Mass: Harvard University Press.

Sorenson, O., \& Stuart, T. 2001. Syndication networks and the spatial distribution of venture capital investments. American Journal of Sociology, 106(6): 1546-1588.

Spicer, A., \& Pyle, W. 2002. Institutions and the vicious circle of distrust in the Russian household deposit market, 1992-1999. In P. Ingram, \& B. Silverman (Eds.), Advances in strategic management: Vol. 19, 373-398. Elsevier Science.

Tsui, A., \& Farh, L. J. 1997. Where guanxi matters, relational demography and guanxi in the Chinese context. Work and Occupations, 24(1): 56-79.

Tsui, A., Farh, J. L., \& Xin, K. 2000. Guanxi in the Chinese context. In J. T. Li, A. Tsui, \& E. Weldon (Eds.), Management and organization in the Chinese context: 225-244. London: Macmillan.

Xiao, Z., \& Tsui, A. 2007. When brokers may not work: The culture contingency of social capital. Administrative Science Quarterly, 52(1): 1-31.

Yakubovich, V. 2005. Weak ties, information, and influence: How workers find jobs in a local Russian labor market. American Sociological Review, 70: 408-421.

Yang, M. 1994. Gifts, favors and banquets: The art of social relationships in China. Ithaca, NY: Cornell University Press.

Bat Batjargal (batjarg@fas.harvard.edu) is Assistant Professor of strategy and entrepreneurship at the Guanghua School of Management of Peking University, and Research associate at the Davis Center, Harvard University. Professor Batjargal earned his DPhil in Political Science from the University of Oxford, England. His research interests are in social networks of entrepreneurs and venture capitalists, institutions, national cultures, gender, religion, cognitions and human capital.
Manuscript received:
April 27, 2006
Final version accepted:
May 2, 2007
Accepted by:
Yanjie Bian 